\title{
Do ambulance crews triage trauma patients?
}

\author{
A. ROUSE
}

Cornwall and Isles of Scilly Health Authority, Senior Registrar, Department of Public Health Medicine, Truro England

\section{SUMMARY}

Objective. To determine whether ambulance crew triage trauma patients appropriately. Design. A retrospective descriptive study. Settings. Cornwall County Ambulance Service. Variables studied. On-scene times, injury severity, establishment of intravenous infusion and time from scene to A\&E department. Subjects. Patients with compound fracture of the lower limb taken to Truro Accident and Emergency department. Outcome measures. Ambulance service on-scene times and mission times. Results. Ambulance crew do not appear to be triaging patients appropriately. Excessive time is being spent on pre-hospital stabilization. Delivery of patients to a casualty department is delayed. Conclusion. At present the activities of paramedics are poorly supervized, and pre-hospital management by paramedics may be jeopardizing patient care.

\section{INTRODUCTION}

Background. Whilst ambulance crews can become proficient in the provision of Advanced Life Support skills it is much less certain that crews use these skills appropriately in field conditions (Border et al., 1983). An important pre-hospital triage skill is identifying when 'scoop and run' or 'stay and stabilize' management is indicated (Champion, 1989). This paper reports studies which sought to assess whether paramedics demonstrated this skill when they dealt with trauma cases.

Correspondence: A. Rouse, Cornwall and Isles of Scilly Health Authority, Senior Registrar, Department of Public Health Medicine, Truro TRI, INR, England. 


\section{MATERIALS AND METHODS}

Location of Study. The study was confined to patients treated at the Royal Cornwalo Hospital (City), Truro.

Case Selections. Patients were needed with injuries which both ambulance and? medical personnel accepted as requiring prompt attention (Rains \& Richie, 1981? Browne, 1988). Cases also had to be readily identifiable from casualty departments records and occur with reasonable frequency. Patients with compound limb fracture meet these criteria.

Case Identification Casualty Department registers were examined and 83 cases of compound fracture of the lower limb transported by ambulance to City hospital Truro between April 1987 and March 1989 were identified.

Measures of Interest. On-scene times: mission times. Figure 1 shows the separaten phases of pre-hospital emergency care

Variables Studied Distance from A\&E department, establishment of intravenous infusion (IV) access and seriousness of injuries.

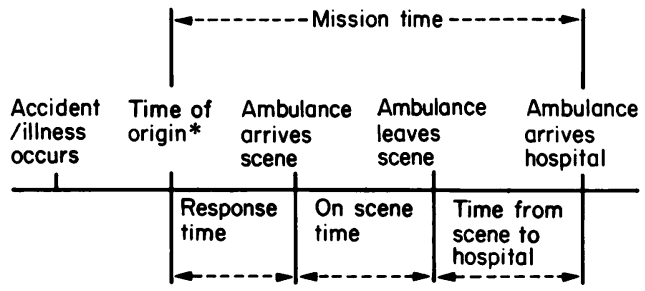

Fig. 1. Phases of pre-hospital emergency care.

\section{RESULTS}

\section{Injury severity}

All the patients identified had injuries requiring surgical intervention: allo 83 patients needed operation under general anaesthesia and 20 of the patients $s^{3}$. studied were very seriously injured: they had multiple other injuries, vascular compromize, shock and amputations.

\section{Pre-hospital deaths}

There were four instances of ambulance service involvement with trauma victims who died prior to reaching hospital. All four had injuries incompatible with life. $\widetilde{N}$

Relationship between long on scene times and mission times

If the principal objective of a pre-hospital trauma service is to deliver patients to hospital rapidly (Champion, 1989), the findings shown in Table 1 are disturbing 
Table 1. Times in minutes for the various phases of pre-hospital care (data from 83 emergency ambulance missions).

\begin{tabular}{lcccc}
\hline & $\begin{array}{c}\text { Arrival at } \\
\text { scene time }\end{array}$ & $\begin{array}{c}\text { On scene } \\
\text { time }\end{array}$ & $\begin{array}{c}\text { Time from } \\
\text { scene to } \\
\text { hospital }\end{array}$ & $\begin{array}{c}\text { Mission } \\
\text { time }\end{array}$ \\
\hline Median $(50 \%)$ & 8 & 28 & 20 & 61 \\
90 percentile & 15 & 53 & 43 & 100 \\
\hline
\end{tabular}

Table 2. To show association between on scene times and mission times.

\begin{tabular}{lcc}
\hline & $\begin{array}{c}\text { *Number of } \\
\text { missions lasting } \\
\text { more than 61 min }\end{array}$ & $\begin{array}{c}\text { *Number of } \\
\text { missions lasting } \\
\text { less than 61 min }\end{array}$ \\
\hline $\begin{array}{l}\text { Number of missions } \\
\text { more than 28 min } \\
\text { on scene }\end{array}$ & & \\
$\begin{array}{l}\text { Number of missions } \\
\text { less than 28 min } \\
\text { on scene* }\end{array}$ & 33 & 8 \\
$\begin{array}{l}\text { Median on-scene } \\
\text { time }\end{array}$ & 10 & 32 \\
\hline
\end{tabular}

* Long missions are greater than the median mission time (61 min).

** Long on scene times are greater than the median on scene time (28 $\mathrm{min})$.

These data suggest that mission times can only be reduced appreciably by shortening on-scene times, and that very little time (and by implication only limited interventions) should be spent on-scene. Table 2 shows very clearly that it is missions with long on-scene times that result in long overall mission times.

\section{On-scene times and the establishment of $I V$ 's}

In these 83 patients no 'advanced skill' other than insertion of IV's was practised. Undoubtedly some of the on-scene time is accounted for by attempts to set up IVs and stabilize patients. For 57 patients, ambulance service and medical records had information recording whether IV access was established. In $53 \%$ of these 57 patients IV access was established. The data presented in Table 3 was obtained by categorizing the severity of injuries using criteria of shock, amputation, crush or other injury. It suggests that severity of injury did not influence whether or not an IV was set up. Longer on-scene times are associated with the establishment of IVs, and the more seriously traumatized patients were no more likely to receive an IV than the less traumatized. 
Table 3. To show on scene times and establishment of IV access.

\begin{tabular}{|c|c|c|}
\hline $\begin{array}{l}20 \text { seriously } \\
\text { traumatized } \\
\text { patients. }\end{array}$ & $\begin{array}{l}37 \text { less seriously } \\
\text { traumatized } \\
\text { patients. }\end{array}$ & \\
\hline IV set up on & IV set up on & Median time \\
\hline 11 patients & 19 patients & on scene $=$ \\
\hline $55 \%$ & $51 \%$ & $40 \mathrm{~min}$ \\
\hline $\begin{array}{l}\text { IV not set up } \\
\text { on } 9 \text { patients }\end{array}$ & $\begin{array}{l}\text { IV not set up on } \\
18 \text { patients }\end{array}$ & $\begin{array}{l}\text { Median time } \\
\text { on scene }= \\
26 \text { min }\end{array}$ \\
\hline $\begin{array}{l}\text { Median on scene } \\
\text { time }=33 \mathrm{~min}\end{array}$ & $\begin{array}{l}\text { Median on scene } \\
\text { time }=33 \mathrm{~min}\end{array}$ & \\
\hline
\end{tabular}

Data for 57 patients carried by the ambulance service whose ambulance service records contain information on IV usage.

Table 4. To show relationship between on-scene times and distance from hospital. Distances from hospital expressed in $\min$.

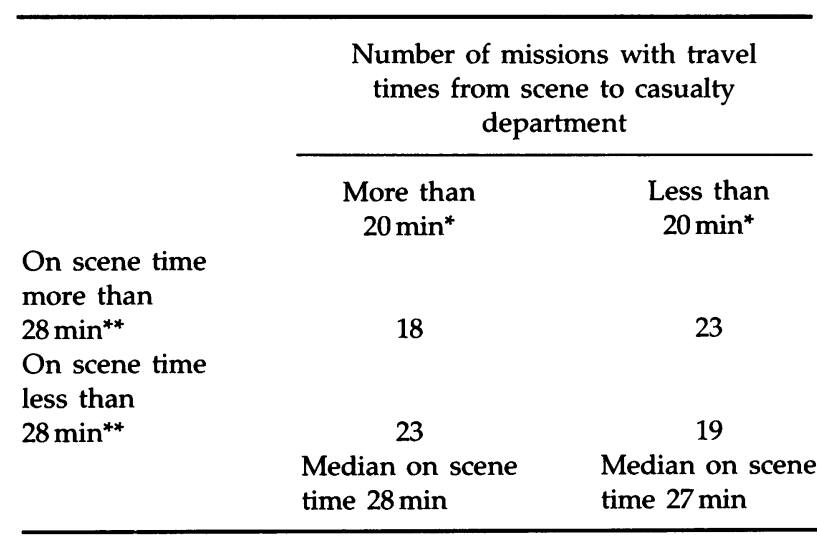

* Median travel time to A\&E department from scene of incident was $20 \mathrm{~min}$.

** Median on scene time was $28 \mathrm{~min}$.

On-scene time and distance from casualty department

Table 4 shows that on-scene times are similar for emergencies occurring close to, or far away from (in time) the casualty department.

\section{DISCUSSION}

There is agreement that the success of any pre-hospital care system depends on $\stackrel{0}{\overline{0}}$ the ability of paramedics to 'triage' patients. For instance, a major triage skill is $\stackrel{\oplus}{\rightarrow}$ 
recognizing when a patient needs to be taken to major casualty department quickly, even if this means bypassing smaller hospitals (Redmond, 1984). However whilst all authorities are agreed that the role of paramedics dealing with patients suffering cardiac arrest is of the greatest importance, some feel that their role in the management of trauma victims is limited (Lewis et al., 1983). There is controversy on whether on-scene stabilization is more appropriate for the trauma patient or if 'scoop and run' management serves the patient better (Redmond, 1984; Alexander, 1989). It is important that the correct management is offered to the patient as the initial hour in the care of the victim of multiple injuries is the critical time for life and limb salvage, and has been termed the 'golden hour of trauma' (Harviel \& Champion, 1989).

\section{Effect of insertion of IV's}

Without proper training and supervision, endotracheal intubation and IV fluid administration can become life-threatening rather than life saving, because they delay the initiation of effective treatment in hospital. Indeed (Alexander, 1989).

'...transport should never be delayed to start intravenous infusion...' (MacKenzie et al., 1988).

In this study the extra on-scene time associated with the insertion of IV's (14 min) is similar to the $10-12 \mathrm{~min}$ noted by others (Lewis et al., 1983). However it need not take long to insert IV's. In Denver, USA. mean on-scene times for missions in which an IV was inserted were only $9.9 \mathrm{~min}$ (Alexander, 1989). Ambulance crews need to be assessed on their ability to insert IV's quickly before they are certified as 'IV trained'. A secondary issue is that crews should be inserting IV's only if there is a clear indication to do so. Attempts to insert IV's should be abandoned if delay in transporting the patient to hospital will result. To do so will probably require the development and implementation of patient management algorithms. Such algorithms have been developed and implemented elsewhere and have been found to be useful. An example is shown in Figure 2.

Discussion with the ambulance service training officer suggests that about $50 \%$ of crews were trained in IV skills, and these crews would invariably have started IVs. Thus it appears that it is the skill level of the ambulance crew and not the clinical need of the patient which decides whether IV access is attempted. In only one instance was more than $500 \mathrm{ccs}$ fluid given. Records were reviewed on the three patients transported by the ambulance service who subsequently died. Their deaths could not be attributed to lack of pre-hospital care.

To conclude, it is unlikely that attempts at on-scene stabilization benefited any

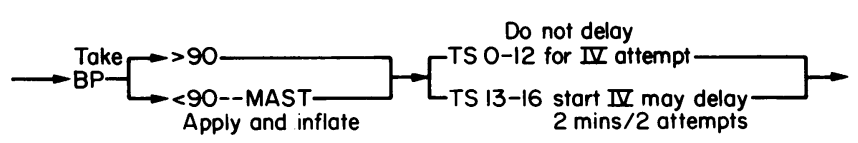

Fig. 2. Example of patient management algorithm Alexander, 1989. BP = blood pressure; MAST = Military anti shock trousers; IV = intravenous infusion and; TS = trauma score. 
patient; rather they delayed their admission to casualty. Almost certainly on-scened times could be reduced with no detriment to patient care.

Why is on-scene time so long?

There is little evidence to explain why on-scene times (median time $28 \mathrm{~min}$ ) are so듬 long. Only in three cases was a cause for delay at the scene noted (awkward access and fire brigade extracting patients). If all the on-scene times were reduced too $15 \mathrm{~min} 72 \%$ of patients compared to the $48 \%$ observed would have been delivered too hospital within $1 \mathrm{~h}$ from time of origin of the call. It must also be remembered that time spent on-scene reduces correspondingly the ambulance service's ability torespond in a timely way to other emergency calls. The problem of overuse ofw paramedic skills to the detriment of overall service performance has been noted by@ others (Litterman et al., 1983).

\section{Distance from hospital}

Senior ambulance personnel agree that when emergency trauma incidents occur close to the casualty department it is generally inappropriate for crews to spendos much time on-scene; scoop-and-run management should prevail. Conversely, stay $\frac{\mathbb{0}}{\mathbb{N}}$ and-stabilize management (with associated longer on-scene times) may be appro- priate at more isolated locations. It is very perturbing that Table 4 shows now evidence to suggest that this very basic triage principal is used. It would appegr that ambulance crews need to be monitored on the time they spend and the? treatments they offer at-scene, preferably within the context of compliance with 'algorithm for pre-hospital treatment'. Distance from hospital needs to be a criterias in this algorithm. Other investigators have noted the necessity of making:-

'. . the distance to hospital. . . a variable incorporated into the decision-makingô process. .' (Litterman et al., 1983).

\section{Role of Medical Directors}

'The quality of pre-hospital triage, treatment and transport systems is largely based on the ability of those systems to be responsive to the state-of-the art: medical direction' (Champion, 1989). 'There must be some medical control in the 3 emergency department to assure that the skills used at the scene are appropriate and are not causing delay' (Lewis et al., 1983). At present the activities of paramedics $₹$ are not satisfactorily monitored by the medical director because a satisfactory crew activity surveillance system is not in place. Attempts are being made to establish such a system.

\section{CONCLUSION}

At present the activities of paramedics are poorly supervised, and pre-hospitale management by paramedics may be jeopardising patient care. 


\section{RECOMMENDATIONS}

The ambulance service needs an improved monitoring system which pays special attention to time spent on-scene and usage of higher skills. Very specific management algorithms need developing, implementing, monitoring and updating.

\section{ACKNOWLEDGEMENTS}

Thanks to M. Sheen and Cornwall and Isles of Scilly Ambulance Service staff, especially Paul Westaway.

\section{REFERENCES}

Border J. R., Lewis F. R., Aprahamian C., Haller J. A., Jacobs L. M. \& Luterman A. (1983) Pre-hospital trauma care - Stabilise or Scoop and Run. The Journal of Trauma 23, (8), 708-709.

Champion H. (1989) Organization of Trauma Care. Treatment of the Trauma Patient. In: Trauma Management, (Ed by D. Kreis \& G. Gonzales.) Little, Brown and Co., London.

Rains A. \& Richie H. (eds) (1981) Injuries to bone, cartilage, ligaments \& tendons; general principles. In: Bailey and Loves Short Practice of Surgery. pp. 347. H. K. Lewis \& Co., London.

Browne P. S. H. (1988) Basic facts of fractures 2nd ed. pp 48. Blackwell Scientific Publications, Oxford. Redmond A. D. (1984) Paramedics in the United Kingdom. British Medical Journal 288, 622-623.

Alexander R. H. (1989) Treatment of the trauma patient. In: Trauma Management (Ed by D. J. Kneis \& G. A. Gomez) pp. 68-71, Little Brown \& Company, London.

Harviel J. \& Champion H. (1988) Early assessment of the acutely injured patient. Current Orthopaedics 2, 99-103.

MacKenzie R. C., Hoyt D. B. \& Sedwitz M. M. (1988) Complications in Trauma Management. In Essential Surgical Practice (Ed by A. Cushieri, G. R. Gillo \& A. R. Moosa) pp. 265. Wright, London.

Litterman A. et al. (1983) Evaluation of pre-hospital Emergency Medical Service; Defining areas for Improvement. The Journal of Trauma 23 (8), 702-707. 